\title{
O TRAUMA PSÍQUICO E O PARADOXO DAS NARRATIVAS IMPOSSÍVEIS, MAS NECESSÁRIAS
}

\author{
Gabriela Maldonado* \\ Marta Rezende Cardoso**
}

\section{Resumo}

Considerando-se, à luz das contribuiçóes freudianas mais tardias, que o traumático, entendido como excesso pulsional, estaria situado além da capacidade de representação psíquica, exploramos neste artigo a estreita articulação entre trauma e "indizível”. Para tal, são retomados alguns aspectos centrais da teorização psicanalítica sobre o trauma, aspectos relacionados com a sua dimensão "intransmissível”. Segundo esta visada, o trauma constitui um vivido que ultrapassa a capacidade psíquica de apropriação e de recalcamento. Nosso objetivo é mostrar como a ideia de uma narrativa impossível, mas absolutamente necessária - eixo central do presente artigo - parece aplicar-se perfeitamente ao sofrimento indizível posto em cena a partir da experiência traumática, e que torna tão fundamental a paradoxal tarefa de narrá-la.

Palavras-chave: trauma; psicanálise; representação; narrativa; memória.

\section{AbSTRaCt}

THE PSYCHICAL TRAUMA AND THE PARADOX OF THE IMPOSSIBLE BUT NECESSARY NARRATIONS

In this paper we examine the strict articulation between trauma and the "unsayable", taking into account that in the light of the latest Freudian contributions, the traumatic, understood

* Psicanalista, Mestre em Psicologia Clínica pela Pontifícia Universidade Católica do Rio de Janeiro (PUC-Rio) e doutoranda do Programa de Pós-Graduação em Teoria Psicanalítica da Universidade Federal do Rio de Janeiro (UFRJ).

** Psicanalista; Professora do Instituto de Psicologia da Universidade Federal do Rio de Janeiro (UFRJ); Pesquisadora do CNPq; Pesquisadora da Associação Universitária de Pesquisa em Psicopatologia Fundamental; Pesquisadora Associada do Núcleo de Pesquisa e Intercâmbio para a Infância e Adolescência Contemporânea (NIPIAC). 
as drive excess, would be situated beyond the capacity of psychical representation. For that, we analyze some central features of psychoanalytical theorizing on trauma, related to its "untransmissible" dimension. From that perspective, trauma constitutes an experience that exceeds the psychical capacity to appropriate and to repress. Our aim is to point out that the idea of an impossible, though absolutely necessary, narration - central axis of this paper-appears to fit the unsayable pain introduced by the traumatic experience, and makes essential the paradoxical task of narrating it.

Keywords: trauma; psychoanalysis; representation; narration; memory.

Em sua raiz etimológica grega, o termo trauma possui o significado de lesão causada por um agente externo. Apropriando-se desta noção, a psicanálise veio a desenvolver o conceito de trauma psíquico, o qual, no período mais tardio da teoria freudiana, a partir da virada dos anos 20, passa a ser entendido, de forma geral, como um afluxo pulsional excessivo, sobrepondo-se à capacidade do psiquismo de ligá-lo e elaborá-lo. Assim, o traumático estaria situado além da capacidade de representação psíquica.

A partir de Freud, numerosos autores têm avançado na pesquisa sobre esse tema, insistindo sobre o fato de que a experiência traumática é aquela que não se representa ainda que deixe, inevitavelmente, marcas indeléveis na memória. Nesse sentido, estabelece-se estreita articulação entre traumático e indizível. É para este caráter praticamente indiscernível entre o vivido traumático e o indizível que parecem apontar as palavras perturbadoras de alguém que experimentou a vida num campo de concentração: "Não que a experiência vivida seja indizível. Ela foi invivível” (Semprun, citado por Seligmann-Silva, 2000: 84).

Nosso objetivo neste artigo é empreender a retomada de alguns aspectos centrais da teorização psicanalítica sobre o trauma, diretamente relacionados com a dimensão "intransmissível” da experiência traumática. É precisamente a impossibilidade de acesso à simbolização o que se coloca no primeiro plano de uma reflexão psicanalítica voltada para a noção de trauma. Esta concepção, segundo a qual o trauma constitui um vivido que ultrapassa a capacidade psíquica de apropriação e de recalcamento, em muito pode ser enriquecida, como tentaremos mostrar, por uma análise das narrativas "simultaneamente impossíveis e necessárias, nas quais a memória traumática, apesar de tudo, tenta se dizer” (Gagnebin, 2006: 49).

A ideia de uma narrativa impossível, mas absolutamente necessária - eixo central do presente artigo -, parece aplicar-se perfeitamente a esse sofrimento 
indizível posto em cena com o traumático e que torna tão fundamental, para aqueles que sobreviveram ao catastrófico do trauma, a paradoxal tarefa de narrar o intransmissível. Que falem por nós as palavras dos sobreviventes das grandes catástrofes históricas, que costumam relatar em seus testemunhos que seus relatos nunca conseguem transmitir realmente as experiências inenarráveis de horror pelas quais passaram ${ }^{1}$.

\section{O FIM DA NARRATIVA: UMA BREVE INCURSÃo NA FILOSOFia de WaLter BENJAMIN}

Como ponto de partida de nossa análise, tomamos de empréstimo, das contribuições filosóficas de Walter Benjamin, um recorte específico de sua teorização em que encontramos uma rica reflexão sobre a experiência do choque e a impossibilidade de se assimilar a vivência traumática pela via de uma narrativa tradicio$\mathrm{nal}^{2}$. A contribuição deste autor revela-se frutífera numa investigação sobre o trauma segundo uma perspectiva psicanalítica, uma vez que algumas de suas proposições podem auxiliar a tentativa de uma melhor delimitação da complexa noção de "irrepresentável”, para a qual o conceito de trauma nos dirige. Entretanto, em função dos limites deste texto, esta contribuição figurará neste trabalho apenas de forma introdutória e bastante condensada.

Em 1933 (1993), Walter Benjamin, escreve "Experiência e pobreza”, ensaio em que aponta para uma fratura da memória na experiência dos soldados que voltaram do front. Este ensaio é iniciado com a constatação de que os sobreviventes que voltaram das trincheiras voltaram mudos. "Na época, já se podia notar que os combatentes tinham voltado silenciosos do campo de batalha. Mais pobres em experiências comunicáveis, e não mais ricos" (Benjamin, [1933] 1993: 115). Conforme a terminologia utilizada por Benjamin, a Primeira Guerra Mundial trouxe como problema crucial o que poderia ser justamente definido como o fim da narrativa tradicional. Os sobreviventes das trincheiras voltavam sem histórias para contar, pois o "invivível” da guerra não podia ser assimilado em palavras. Para Benjamin, a experiência traumática da guerra não seria uma experiência transmissível "de boca em boca" (Benjamin, [1933] 1993: 115), por tratar-se de uma experiência única e não compartilhável, que tende a aniquilar a possibilidade de outras experiências.

Retomando essa tese, Márcio Seligmann-Silva (2000), atento ao alcance das propostas de Benjamin, avança na reflexão sobre a questão da representação de catástrofes, advertindo-nos sobre o caráter de literalidade que seria próprio da 
recordação da cena traumática: "A recordação do momento de transbordamento é, na maioria dos casos, extremamente acríbica" (Seligmann-Silva, 2000: 85). Segundo o autor, a literalidade que caracteriza o sintoma traumático resultaria de um excesso de realidade que inviabiliza a estratégia de representação do trauma por metáforas. A narrativa literal do trauma adviria da experiência onipresente da morte, a qual, no contexto da guerra, é trivial, arbitrária, violenta e absurda:

Dá-se uma cisão do Eu. Essa realidade em excesso implica um "perfuramento" do próprio campo (geográfico, simbólico e semântico) da morte: esta, devido à sua onipresença, deixa de ocupar o seu papel fundamental na organização simbólica; ela não orienta mais a distinção entre o aqui e o além (Seligmann-Silva, 2000: 93).

A figura de narração, que Benjamin associa à vivência do choque, pode ser ilustrada, como bem observa Jeanne-Marie Gagnebin (2006), pelo sonho de Primo Levi no campo de Auschwitz, sonho que, segundo ele, seria comum a todos os prisioneiros do campo. Sonhavam que, ao retornar à casa, tentavam contar aos outros os horrores pelos quais haviam passado mas, para desespero deles, ninguém queria escutar o que aconteceu; simplesmente levantavam-se e iam embora, indiferentes. Essa recusa se expressa de forma contundente no questionamento inquietante de Primo Levi: "Por que o sonho de cada dia se traduz, constantemente, em nossos sonhos, na cena sempre repetida da narração que os outros não escutam?” (Levi, 1988: 60). No testemunho de outra sobrevivente dos campos de concentração, encontramos corroborada essa ideia de uma narração-transmissão impossível, desta vez não sonhada, mas bem real:

[...] sempre pensava que teria algo de interessante para dizer depois da guerra. Mas as pessoas não querem ouvir, ou somente o fazem com uma certa pose, uma certa atitude não como interlocutoras e sim como pessoas que se submetem a uma tarefa desagradável, em uma espécie de reverência que facilmente se transforma em repugnância, duas sensações que em todo caso se complementam. Pois tanto o objeto da reverência como o da repugnância são sempre mantidos à distância (Kluger, 2005: 102).

Assim, a libertação dos sobreviventes revela-se especialmente angustiante, já que aqueles que não vivenciaram o campo de concentração tenderiam a não suportar ouvir as suas histórias, testemunho de uma radical experiência de descontinuidade histórica. 


\section{TRAUMA E NARRATIVA: CONTRIBUIÇÕES CONTEMPORÂNEAS}

Quero viver um dia depois de Hitler, um dia depois do fim da guerra. [...] E estamos aqui para lhe contar a história.

(Fortunoff, T58)

Ao tematizar a ideia de uma narrativa impossível, mas necessária, Márcio Seligmann-Silva (2000), baseando-se na teoria freudiana do trauma e explorando as propostas de Walter Benjamin, desenvolve a interessante ideia de ferida na memória diante do catastrófico da experiência traumática. $\mathrm{O}$ autor se pergunta como o sujeito poderá vir a testemunhar o irrepresentável, dando uma forma àquilo que viria transbordar a sua capacidade de pensar.

Conforme ressaltamos anteriormente, a conceituação psicanalítica sustenta que aquilo que é da ordem do trauma implica a ideia de algo inassimilável ao mundo psíquico, ainda que deixe marcas indeléveis na memória. Essas marcas, que irão retornar sob os determinismos cegos e mudos da compulsão à repetição (Freud, [1920] 1974) sem que tenham podido ser elaboradas, compõem aquilo que, conforme as indicações de Alain Fine (2002), André Green (2002) muito apropriadamente denomina "memória amnésica" e cuja manifestação se dá sob a forma de somatizações e despersonalizações. Voltaremos a este aspecto mais adiante.

A noção de memória amnésica nos faz pensar no que Seligmann-Silva (2007), em comunicação oral, tratou como "memória de um passado que não passa”, conduzindo-nos à ideia de que as marcas deixadas por um evento traumático vêm instalar um presente contínuo. Portanto, estas não se inscrevem como passado, porque não podem ser esquecidas - em função de seu retorno sob a forma de repetição dolorosa. É em razão desta peculiaridade da memória traumática que o autor sustentará, nessa mesma conferência, que "na situação testemunhal o tempo passado é tempo presente”.

Estando o traumático situado no campo do "além do princípio de prazer", podemos considerá-lo, então, como um conceito-limite. Limite, porquanto referido aos limites da capacidade de simbolização do aparato psíquico, ao mesmo tempo que, por esta mesma razão, vemo-nos aqui diante dos limites da psicanálise, em sua prática tanto clínica, quanto teórica. Tendo em vista a dimensão de catástrofe que comporta, o trauma, por definição, vem sempre deslocar o sujeito de seu lugar na cadeia de simbolização. Esta forma de considerar o traumático como estado limite do psíquico encontra eco nas palavras de Knobloch: "O traumá- 
tico aparece pela impossibilidade de representação, como um estado limite do psíquico, não elaborado e desorganizado, que pode ser 'qualificado' de não representável" (Knobloch, 1998: 94).

Esse deslocamento ao campo do irrepresentável, operado pelo vivido traumático, tem como um de seus efeitos a produção de um estranhamento. Referindo-se aos sobreviventes de catástrofes históricas, Seligmann-Silva (2007, na comunicação oral acima referida) sustenta que: "algo da cena traumática permanece incorporado como um corpo estranho, estranhamento pelo fato de ter morado do outro lado do campo simbólico". É desse exílio do "campo simbólico" que se impõe a fundamental necessidade para aquele que viveu a experiência do trauma de contar para um outro o que foi vivido. Esta atividade de narrativa-testemunho, esse contar ao outro, implica, nas palavras proferidas pelo autor, a sobrevida daquele que passou por uma catástrofe, pois os que testemunharam são necessariamente aqueles que não sucumbiram. De fato, a profusão, neste século, de autobiografias e literaturas de testemunho, relatos da experiência dos que voltaram dos campos de concentração, vem endossar esta posição.

Por outro lado, para que esta narrativa seja possível, é preciso que seja feita a partir de algo que pôde ser conservado da experiência traumática. Assim, parecenos fértil darmos seguimento à nossa reflexão através da trilha da memória.

\section{A TEORIA FREUDIANA DA MEMÓRIA E A FUNÇÃO DA RECORDAÇĀO}

O objetivo do tratamento, desde os primórdios da obra de Freud, consistia em tornar conscientes as lembranças recalcadas. Mas, no seio de uma importante modificação teórico-clínica na qual a noção de realidade psíquica assumiu um estatuto fundamental, Freud conclui que o recordado não coincide com os acontecimentos em si. Estes já constituem um material processado e transformado psiquicamente, resultado de um complexo processo de múltiplas retranscrições, no qual a experiência passada é ressignificada no contexto das experiências atuais. O trabalho psíquico incide sobre as recordações ao longo de diferentes épocas da vida, modificando-as segundo novas circunstâncias. Retomemos, neste ponto, a célebre carta a Fliess, a de número 52:

o material presente em forma de traços de memória estaria sujeito de tempos em tempos a um rearranjo segundo novas circunstâncias - a uma retranscrição. Assim, o que há de essencialmente novo a respeito de minha teoria é a tese de que a memória não se faz presente de uma só vez, mas se desdobra em vários 
tempos; que ela é registrada em diferentes espécies de indicações [...] os sucessivos registros representam a realização psíquica de épocas sucessivas da vida (Freud, [1896a] 1974: 254-5).

A tese freudiana de retranscrição dos traços de memória articula-se com a noção de a posteriori. Somente haveria trauma psíquico na posterioridade do acontecimento traumático. Haveria uma retroatividade, uma ação póstuma do trauma, através da lembrança. Nos termos da "Carta 52", após o trauma ocorre um rearranjo, um efeito de tempo, através do qual os eventos traumáticos adquirem significação para o sujeito, significação, portanto, "só-depois" (nachträglich), pela via de um processo de reconstrução. "O traumático consistiria, então, na articulação destes dois tempos, enquanto ressignificação que o segundo momento traz para o primeiro" (Knobloch, 1998: 38).

Esta ideia de transformação posterior, que ressignifica as lembranças, coincide com aquela que também fundamenta a suposição de que "os histéricos sofrem principalmente de reminiscências" (Freud, [1893] 1974: 45), ideia cujo desdobramento aparece na tese de que o aparato psíquico constitui fundamentalmente um aparato de memória, sujeito a rearranjos e retranscriçōes, num processo em que traços mnêmicos do passado "sobrevivem", distorcendo o vivido atual do sujeito. Essas "sobrevivências" foram denominadas por Freud de fueros.

Tratar-se-ia de uma realidade encoberta (Duparc, 2001-2002), sujeita a reconstruções, remodulações, de acordo com a história de vida de cada sujeito, promovendo diferentes modos de resolução do traumático. Isto nos permite afirmar que, de acordo com a teoria freudiana da memória, "a verdade" não estaria oculta à espera de ser encontrada, mas estaria sempre enlaçada no relato que dela se faz. Melhor dizendo, numa análise, nunca entramos em contato com o acontecimento original, mas sim com a descrição que o paciente faz dele, e que já estaria sujeita aos efeitos de deformação da memória e do aprés-coup. No marco dessa elaboração, a importância da "verdade histórica” (Freud, [1918] 1974) é substituída pela importância da verdade narrativa, tendo em vista que esta estaria enlaçada à experiência do sujeito, mas já deformada pela lembrança encobridora e, portanto, pelos efeitos da fantasia.

Esta constatação abre a seguinte questão: se a verdade própria ao campo inaugurado por Freud é a verdade narrativa, e se o acontecimento traumático é da ordem do irrepresentável, que figura de narração seria suscetível de assimilar o indizível do trauma? Ou ainda: que concepção de representação permitiria a inclusão desse vivido cujo efeito costuma ser identificado como um corpo estranho que permaneceria incrustado na "alma”? A elaboração destas questões exige, num 
primeiro passo, a problematização da noção de irrepresentável, e sua relação com o traumático. Mas antes de ingressarmos nesta vertente de análise desejamos ainda sublinhar que, muito embora o termo "irrepresentável" não tenha sido utilizado por Freud, podemos inferi-lo de suas formulações sobre o traumático, sobretudo a partir da virada dos anos 20 com a introdução do conceito de pulsão de morte. Não é nossa intenção, entretanto, explorar diretamente essa essencial mudança operada na obra freudiana teórica, mas apenas deixar indicado, a este propósito, que a ideia de excesso pulsional, força que não pode ser mediada pela representação, constitui, no nosso entender, o próprio cerne no novo dualismo pulsional.

\section{O TRAUMA AQUÉM DA REPRESENTAÇÃO}

\section{É surpreendente que se tenha tão pouco a dizer justamente a respeito de aconteci-} mentos tão extremos. A linguagem humana foi inventada para outros fins. (Kluger, 2005: 169)

Revendo a teoria freudiana da memória, somos remetidos a duas direções. Por um lado, esta teoria nos fala da possibilidade de uma "verdade" a ser retranscrita e, portanto, construída através de um processo de estratificações, processo capaz de modificar o núcleo de verdade histórica do "acontecimento original". Esta seria a memória regida pelo campo da sexualidade, memória regulada pelo princípio de prazer e pela lógica do a posteriori, o que leva a supor que a "verdade" a ser narrada traz a marca de uma lembrança encobridora. Trata-se aqui de uma narrativa submetida a uma memória ligada aos desejos inconscientes. Nesse contexto, a história narrada traz o crivo dos efeitos do recalcamento e da tela encobridora da fantasia, protegendo o sujeito dos "horrores" da ruptura traumática: a literalidade pós-traumática.

Por outro lado, quando pensamos na memória traumática, à luz, por exemplo, da "Carta 52" e tendo como horizonte a noção de fueros, estamos diante de uma dimensão que é, a um só tempo, repetitiva, imutável e que não se inscreve. Ao fazermos referência a uma experiência que não se inscreveu, temos como base o registro da representação. Esta memória não estaria referida ao recalcado, nem submetida ao Princípio de Prazer. Alinhados com o pensamento de Alain Fine (2002), que, a este respeito, afirma basear-se em algumas das afirmações de André Green (2002), poderíamos classificá-la como memória imemorável. Mas a ideia paradoxal de uma memória amnésica é, em última instância, tributária, segundo Alain Fine, da noção freudiana de fueros. 
Assim, o evento traumático viria inserir-se numa rede inconsciente de experiências vividas, mas que curiosamente não teriam uma característica equivalente à de outros objetos mnésicos, tais como a lembrança. A intensidade de sua atualização, tal como aparece nos fenômenos de compulsão à repetição, "situa estes fenômenos mais como equivalentes de lembranças conotadas de uma realidade alucinatória do que como equivalentes da lembrança em si" (Fine, 2002: 2; tradução nossa). Segundo a concepção freudiana, quando se dá uma impressão traumática, tratar-se-ia de uma impressão que não deixou traços no psiquismo, tratar-seia de marcas, tendo em vista a sua exterioridade em relação à linguagem e à significação. Essa impressão traumática não vem a se ligar aos traços preexistentes, não podendo, então, ser mediatizada pela lembrança, já que não se inscreveu. É neste sentido que alguns autores, tais como Uchitel (2001), Knobloch (1998) e Reis (2004), irão relacionar o traumático à dimensão de "apresentação", de "mostração" ou "presentificação": "O trauma não se representa, apresenta-se" (Uchitel, 2001: 77).

O que estamos aqui tratando como imemorável do trauma, orquestrado pelo poder compulsivo da repetição traz, no lugar do "representado", o "agido", e no lugar da "lembrança" - que é sempre uma retranscrição - a "repetição" do mesmo. Os chamados estados limites, assim como as neuroses de guerra, ilustram, no contexto da clínica, a particularidade de uma memória traumática: ela é literal (repete o mesmo), imemorável (passado é presente), inumana (da ordem das marcas, e não de traços significativos). Vale insistir que a memória traumática está situada além do princípio de prazer, convocando o "mortífero". Portanto, não se confunde com uma memória da "representação". Talvez possamos pensá-la como memória "afetiva", memória corporal.

Esta posição é sustentada, por exemplo, por Reis (2004), em "Corpo e memória traumática”. Neste artigo, a autora apresenta a fecunda hipótese segundo a qual a memória traumática é registrada como signos de percepção ou impressões sensiveis, já que se faz presente por manifestaçôes corporais da ordem da repetição e da ação desagregadora da pulsão de morte no interior do eu. Tratar-se-ia de uma memória ligada ao registro da sensibilidade, memória ligada ao corpo. Reis defende a ideia de que determinadas vivências traumáticas subsistiriam somente como impressões sensíveis; são marcas deixadas pelo evento traumático que instalam um presente contínuo, sem abertura para evocação de um passado. O tempo do trauma é, portanto, o da urgência, o do imediatismo.

Segundo este ponto de vista, o traumático se apresenta como exigência de presentificação, pela via da repetição do mesmo, e não como historicização. Ter memória é poder historicizar, o que no plano do trabalho psíquico seria equiva- 
lente de poder vir a ser "inscrito". No imemorável do trauma, se o tempo passado é "cristalizado" no tempo presente, então, como bem observou Lissovsky (2007), o futuro, para "o narrador" de uma catástrofe, não é o futuro do presente, mas um futuro do pretérito, no qual aquilo que "será" é substituído pelo que "poderia ter sido". Essa ruptura entre dois tempos é efeito de uma vivência extrema que tenderia a cindir a vida em duas partes: antes do trauma e depois do trauma.

Como é sabido, essa dimensão de cisão foi bastante explorada por Sandor Ferenczi ([1934] 1992) através do conceito de clivagem narcísica. Diante da ameaça de morte psíquica, o ego, como estratégia de sobrevivência, fragmenta-se em várias partes que não se comunicam entre si. Este mecanismo tem por objetivo manter separados certos conteúdos psíquicos que não irão se vincular a uma cadeia representacional. Nesse sentido, o mecanismo da clivagem "demonstra que não houve mediação entre dois modos diferenciados de uso da linguagem, que a descontinuidade foi tão extensa que não permite que os seus constituintes sejam percebidos como integrados imaginariamente numa mesma unidade narcísica" (Vertzman, 2002: 70).

O efeito do traumático constituiria, portanto, não somente a impossibilidade de registro, mas a destruição de conjuntos antes agregados e vinculados por associações. De acordo com esta visão, não seriam exatamente os conteúdos que seriam destruídos, mas os elos de ligação entre eles. Neste caso, estamos aquém do mecanismo de recalcamento, estamos situados mais além do prazer, que nos fala de ruptura, de desligamento, de desconexão do que antes estava ligado, provocando fragmentações na integridade do ego. Quando o aparelho psíquico é atingido por quantidades excessivas de energia, são acionadas defesas muito arcaicas, defesas que estariam aquém de qualquer possibilidade de recalcamento, pois se trata, sobretudo, de uma tentativa desesperada de manter a vida. Nesses casos não há o que recordar, só o que repetir.

O traumático parece-nos marcado, então, pela literalidade, ao contrário dos vividos psíquicos agenciados pelo processo de recalcamento, envolvendo formações de compromisso e encontrando expressão no sintoma ou numa infinidade de formas de satisfações substitutivas. O traumático nos revela, ao contrário, um perfuramento no sistema para-excitação (Freud, [1920] 1974), que virá a se apresentar como "clarão" insuportável, num flashback pós-traumático hiper-real, sem mediação, sem, portanto, a possibilidade de "esquecimento". Quando se rompe o sistema "para-excitação", rompe-se também a tela protetora da fantasia que teria a função de encobrir, revestir o horror.

No terreno do trauma, as lembranças não são encobridoras, relativas ao recalcamento, mas são lembranças relativas à clivagem, como mecanismo que promove fragmentação e divisão do eu em partes incomunicáveis. É assim que en- 
contramos, na literatura dedicada ao tema do traumático, a ideia de algo enquistado (ver, por exemplo, Cardoso, 2002; 2007) que com o tempo não se dilui, não se suaviza; elementos indeléveis e, por isso mesmo, paradoxalmente indizíveis.

Concluindo provisoriamente esta breve reflexão, que demanda certamente ainda muitos aprofundamentos, queremos pontuar, à luz das contribuiçôes extremamente atuais de Freud, que o traumático é aquilo que retorna como signos perceptivos que não se submetem ao deciframento do inconsciente e que resistem a serem expressos em palavras (Freud, [1896b] 1974). Por não ingressarem numa rede associativa, estes signos perceptivos se fazem presentes sob a forma de repetições, de atos, manifestações corporais e não de formaçôes substitutivas (Reis, 2004). A marca deixada pelo vivido traumático tende a permanecer enquistada no psiquismo como um corpo estranho radical, "como um projétil de chumbo que não se pode retirar do corpo" (Kluger, 2005: 126), insistindo em se apresentar sob a forma de conteúdos que não circulam. Ao se apresentar, e estando aquém de toda possibilidade representacional, o trauma pode ter como resposta extrema a condução do sujeito à paralisia e à morte psíquica (Ferenczi, [1932] 1990; Freud, [1920] 1974).

Se, por um lado, o trauma aponta para uma narrativa impossível, pelo excesso de realidade que comporta, por outro, paradoxalmente, vimos o quanto é importante para aquele que experimentou uma situação traumática poder relatar ao outro sua história, endereçar um testemunho à escuta de alguém que possa, com essa atitude, vir a promover a abertura de uma possibilidade de representação do “inominável”. Afirma Gagnebin (2000) que "só se pode, paradoxalmente, respei$\operatorname{tar}[\ldots]$ a experiência-limite dos sobreviventes se se acolhe o silêncio e a interrogação que provocam" (Gagnebin, 2000: 108).

Este paradoxo reforça o duplo aspecto que o trauma comporta: a impossibilidade e a necessidade de sua representação. Diante do traumático, um testemunho se assenta necessariamente sobre a experiência-limite de um narrador que perfurou a barreira entre a vida e a morte.

\section{REFERÊNCIAS BIBLIOGRÁFICAS}

Benjamin, W. (1933/1993). Experiência e pobreza. Em Magia e técnica, arte e politica (pp. 115-119). São Paulo: Brasiliense.

Cardoso, M. R. (2002). Superego. São Paulo: Escuta.

. (2007). Les états limites: la question du pouvoir de l'autre. Em Marty, F.

Transformer la violence? Traumatisme et symbolisation (pp. 176-194). Paris: Press Editions. Celan, P. (1999). Cristal. São Paulo: Iluminuras. 
Duparc, F. (2001-2002). Des traumatismes invisibles ou par manque de réalité. Conférence Vulpian. Societé Psychanalytique de Paris. Disponível em <http://spp.asso.frSocietéPsychanallytique>. Acesso em 1/1/2008.

Esteban, E. (1993). Malvinas: diario del regreso. Buenos Aires: Sudamericana.

Felman, S. (2000). Educação e crise ou as vicissitudes do ensinar. Em Nestrovsky, A. \& Seligmann-Silva, M. (orgs.). Catástrofe e representação (pp. 73-98). São Paulo: Escuta. Ferenczi, S. (1932/1990). O que é o “trauma”. Em Diário clínico (pp. 227-229). São Paulo: Martins Fontes.

(1934/1992). Reflexões sobre o trauma. Obras completas, v. IV. São Paulo: Martins Fontes.

Fine, A. (2002). Fixation au trauma; réssurgence, élaboration. Conférence Vulpian, Maio, 2002. Société Psychanalytique de Paris. Disponível em <http://spp.asso.frSocietéPsychanallytique>. Acesso em 1/1/2008.

Freud, S. (1893/1974). Sobre o mecanismo psíquico dos fenômenos histéricos: comunicação preliminar. Obras completas, ESB, v. II. Rio de Janeiro: Imago.

- (1896a/1974). Carta 52. Obras completas, ESB, v. I. Rio de Janeiro: Imago. . (1896b/1974). Hereditariedade e a etiologia das neuroses. Obras completas, $E S B$, v. III. Rio de Janeiro: Imago.

- (1918/1974). História de uma neurose infantil. Obras completas, ESB, v. XVII. Rio de Janeiro: Imago. . (1920/1974). Além do princípio de prazer. Obras completas, ESB, v. XVIII.

Rio de Janeiro: Imago.

Gagnebin, J. M. (2000). Palavras para Hurbinek. Em Nestrovsky, A. \& Seligmann-Silva, M. (orgs.). Catástrofe e representação (pp. 73-98). São Paulo: Escuta.

—. (2006). Memória, história e testemunho. Em Gagnebin, J. M. Lembrar, escrever, esquecer (pp. 49-57). São Paulo: Editora 34.

Green, A. (2002). La diacronia en psicoanalisis. Buenos Aires: Amorrortu.

Kluger, R. (2005). Paisagens da memória: autobiografia de uma sobrevivente do holocausto.

São Paulo: Editora 34.

Knobloch, F. (1998). O tempo do traumático. São Paulo: EDUC.

Levi, P. (1988). É isto um homem? Rio de Janeiro: Rocco.

Lissovsky, M. (2007). Aula proferida na disciplina Psicanálise e linguagem, ministrada pela

Professora Regina Herzog no Programa de Pós-Graduação em Teoria Psicanalítica da UFRJ (julho-novembro/2007).

Reis, E. S. (2004). Corpo e memória traumática. Trabalho apresentado no I Congresso Internacional de Psicopatologia Fundamental e VII Congresso Brasileiro de Psicopatologia Fundamental. Rio de Janeiro, 2004. Disponível em <http:// 
br.geocities.com/memoria_pensante/corpo_mem_traum_schueler.html>. Acesso em 1/ $1 / 2008$.

Seligmann-Silva, M. (2000). A história como trauma. Em Nestrovsky, A. \& SeligmannSilva, M. (orgs.). Catástrofe e representação (pp. 73-98). São Paulo: Escuta. . (2007). Narrar o trauma: a questão dos testemunhos de catástrofes históricas. Comunicação apresentada no Encontro Nacional Trauma e Memória, Rio de Janeiro/ PUC-Rio, Junho de 2007.

Uchitel, M. (2001). Neurose traumática: uma revisão crítica do conceito de trauma. São Paulo: Casa do Psicólogo.

Vertzman, J. S. (2002). O observador do mundo: a noção de clivagem em Ferenczi. Ágora: estudos em Teoria Psicanalitica, v. 5, no 1, 59-78.

\section{Notas}

1 Ver Ruth Kluger (2005), Primo Levi (1988), Edgardo Esteban (1993), Paul Celan (1999), dentre outros.

2 A narrativa tradicional é uma figura de narração que aponta para uma instância de sentido, é uma narrativa que incorpora os acontecimentos articulando-os a uma estrutura previamente existente. Ver a aula proferida por Maurício Lissovsky sobre a obra de Walter Benjamin (Outubro/2007) na disciplina Psicanálise e linguagem ministrada pela Professora Regina Herzog (julho-novembro/2007).

3 Testemunho de sobrevivente dos campos de concentração, gravado em fita de vídeo, da Fortunoff Video Archive for Holocaust Testemonies at Yale. Ver Felman (2000).

Recebido em 29 de dezembro de 2007 Aceito para publicação em 14 de maio de 2008 